\title{
ДИЗАЙН НОВЫХ ХИМИЧЕСКИХ ТРАНСФОРМАЦИЙ С ИСПОЛЬЗОВАНИЕМ АЛИФАТИЧЕСКИХ НИТРОСОЕДИНЕНИЙ ДЛЯ ПОЛУЧЕНИЯ БИОЛОГИЧЕСКИ АКТИВНЫХ ПРЕПАРАТОВ
}

\author{
А.В. Аксенов ${ }^{1}$, Д.А. Аксенов', Н.А. Аксенов' , И.В. Аксенова', \\ М.А. Рубин ${ }^{1,2}$ \\ ${ }^{1}$ Химико-Фармацевтический факультет, Северо-Кавказский федеральный университет, \\ 355017, Россия, г. Ставрополь, ул. Пушкина, д. 1. \\ 2 Department of Chemistry, University of Kansas, \\ 1567 Irving Hill Rd., Lawrence, KS 66045-7582, USA.
}

DOI: 10.19163/MedChemRussia2021-2021-14

E-mail: aaksenov@ncfu.ru

Создание новых классов лекарственных препаратов является актуальной задачей, в решение которой вовлечено значительное число научных коллективов. Особое место занимает поиск новых молекулярных каркасов для поиска противоопухолевых препаратов и более эффективных путей синтеза уже известных структур с противораковой активностью.

В последнее время среди новых синтетических методов большое значение приобретают: metalfree C-H -функционализация, трансаннелирование, ring economy - процессы. Именно развитию таких методологий в сочетании с методологией, включающей дизайн “умных реакционных сред”, которая успешно развивается в нашей лаборатории, посвящен этот доклад. Он включает разработку методов синтеза на основе реакций индолов с непредельными нитросоединениями и нитроалканами. Основываясь на этой методологии, удалось получить большое количество соединений с высокой противораковой активность, причем ряд веществ проявляют редкое свойство - обратную дифференциацию. Некоторые соединения обладают противопаразитарной активностью в отношении лейшманиоза.

Работа выполнена при финансовой поддержке РНФ грант 18-13-00238, 21-73-20051, РФФИ грант 19-03-00308, а также Министерства образования и науки Российской Федерации (тема 0795-2020- 0031). 